\title{
Leaf wetting mitigates midday depression of photosynthesis in tomato plants
}

\author{
G. YOKOYAMA*, D. YASUTAKE ${ }^{* *+}$, T. TANIZAKI*, and M. KITANO** \\ Graduate School of Bioresource and Bioenvironmental Sciences, Kyushu University, 812-8581 Fukuoka, Japan* \\ Faculty of Agriculture, Kyushu University, 6-10-1 Hakozaki, Higashi-ku, 812-8581 Fukuoka, Japan**
}

\begin{abstract}
We studied the effects of leaf wetting on midday depression of photosynthesis regarding plant water balance and leaf morphological traits. The plants without leaf wetting showed a significant reduction in midday photosynthesis with a concomitant decrease with leaf conductance, because of lower leaf water potential $(-1.3 \mathrm{MPa})$ due to excessive transpiration water loss. However, midday depression was not observed in the plants with leaf wetting. Lower contact angle between leaf surface and water droplet showed that tomato leaves have lower water repellency. However, water on the leaf surface completely dried within 20 min indicating that effect of water coverage on stomata for $\mathrm{CO}_{2}$ uptake was small. In addition, leaf wetting significantly decreased evaporative demands, which contributed to maintaining appropriate water balance and avoided midday stomatal closure, and it contributed to mitigation of midday depression of photosynthesis.
\end{abstract}

Additional key words: plant water relations; photosynthetic rate; stomatal conductance; transpiration rate; whole-plant chamber.

\section{Introduction}

Plants actively perform photosynthesis on sunny days, but often the photosynthetic rate drops around midday even in plants exposed to sufficient sunlight for photosynthesis. This reduction in photosynthesis, known as a midday depression of photosynthesis, has been frequently observed in various crops grown in both open fields (Hirasawa et al. 1989, Hu et al. 2009) and greenhouses (Ayari et al. 2000, Pelletier et al. 2016). Because photosynthesis is an important biochemical process for crop growth and yield, a midday depression of photosynthesis could be a limiting factor for crop production.

It has been reported that stomatal limitation is one of the major causes of midday depression of photosynthesis under mild to moderate water stress (Flexas et al. 2004, Grassi and Magnani 2005). On sunny days, higher levels of irradiance around midday increase evaporative demand and induce stomatal closure in response to excessive transpiration water loss if enough water cannot be supplied to the sites of evaporation on leaves (Kitano and Eguchi 1993). Because of hydraulic resistance through plant water pathways, imbalances between water supply and demand often occur in plants even when the rooting zone is well-watered (Schulze 1986). In addition, recent studies have shown that leaf hydraulic conductivity is a critical bottleneck in whole-plant water transport (Sack and
Holbrook 2006), and this decreases as leaf water potential declines (Guyot et al. 2012). Thus, reductions in leaf water potential as a result of transpiration water loss may induce further stomatal closure. Although nonstomatal limitations such as photoinhibition (Long et al. 1994, He et al. 2007) and carbohydrate accumulation in leaves (Araya et al. 2006) have also been reported to cause midday depression, stomatal limitation is predominately responsible for, or at least partially involved in, the occurrence of midday photosynthetic depression.

It has long been believed that soil water is the only significant water source contributing to plant water balance, and therefore, to productivity (Mather and Yoshioka 1968, Stephenson 1990). However, recent studies have revealed that leaf wetting by dew, fog, or cloud-borne mist may act as a water subsidy in many ecosystems, with positive effects on plant water balance (Limm et al. 2009, Eller et al. 2013). Leaf wetting affects the microclimate near the leaf surface, which dominates the gas exchange between the leaf surface and the atmosphere. Higher levels of atmospheric humidity and suppression of rises in leaf temperature could reduce evaporative demand, leading to lower rates of transpiration water loss (Limm et al. 2009, Yasutake et al. 2015). Such effects of leaf wetting may provide physiological benefits, for instance by increasing photosynthesis through stomatal openings (Hanba et al. 2004). Another benefit of leaf wetting is direct water

\footnotetext{
Received 9 September 2018, accepted 18 December 2018.

${ }^{+}$Corresponding author; fax: +81-92-642-2924, e-mail: yasutake@bpes.kyushu-u.ac.jp

Abbreviations: $C_{\mathrm{a}}-$ atmospheric $\left[\mathrm{CO}_{2}\right] ; C_{\mathrm{i}}-\left[\mathrm{CO}_{2}\right]$ in the substomatal (intercellular) airspace; $E$ - transpiration rate; $e_{\mathrm{A}}-$ vapor pressure near leaf surface; $e_{\mathrm{L}}$ - leaf vapor pressure; ET - evapotranspiration rate; $g_{\mathrm{L}}-$ leaf conductance; $P_{\mathrm{N}}-$ net photosynthetic rate; $T_{\mathrm{L}}-$ leaf temperature; VPD - vapor pressure deficit; $\mathrm{VPD}_{\text {air-to-leaf }}$ - vapor pressure deficit between air and leaf; $\Psi_{\mathrm{w}}-$ leaf water potential. Acknowledgements: Financial support for this study was provided by Grants-in-Aid for Scientific Research (JSPS KAKENHI grant no. JP18K05905 and JP17H03895) from the Japan Society for the Promotion of Science.
} 
absorption through the leaf surface, otherwise known as foliar water uptake (Simonin et al. 2009). This phenomenon has been reported in several woody plants, and provides benefits, such as an increase in leaf water potential, and consequently, increases in plant photosynthetic activity, growth, and survival under drought conditions (Cassana and Dillenburg 2013, Eller et al. 2016). Thus, leaf wetting may positively affect leaf water balance by reducing transpiration water loss and increasing leaf hydration by foliar water uptake.

However, leaf wetting is considered unfavourable for horticultural crops because the duration of leaf wetness is related to the incidence of plant disease (Huber and Gillespie 1992). In addition, leaf wetting can block $\mathrm{CO}_{2}$ uptake via stomata (Ishibashi and Terashima 1995). Thus, studies on the positive effects of leaf wetting on horticultural crops are limited. Leaf wetting may have either positive or negative effects on horticultural crops. One clue to this question is the hydrophobicity of the leaf surface, because the different responses of plant photosynthesis to leaf wetting have been explained from the perspective of leaf surface repellency (Hanba et al. 2004): if leaf water repellency is high, the effect of leaf wetting is positive, whereas if repellency is low, then the effect is negative. Another factor that may influence the effect of leaf wetting is a plant water status, as most studies have reported positive effects of leaf wetting on drought stressed plants (Simonin et al. 2009, Cassana and Dillenburg 2013). When the water potential gradient between the leaf and the wetted leaf surface is large, leaf surface water may be absorbed from the leaf surface and contribute to plant rehydration. Because of the complexity of the effects of leaf wetting on plants, only a handful of studies have examined its effects on horticultural crops, for example, the effects on plant water status (Ozawa 1989) and gas exchange (Yokoyama et al. 2018). Thus, little is known about the effects of leaf wetting on midday depression of gas exchange or the role of other factors, such as morphological traits and water status influencing its effects.

In this study, we examined the effects of leaf wetting on midday depression of gas exchange and leaf water potential in tomato plants, basing our assumption on the hypothesis that midday depression is induced by excessive transpiration water loss. To evaluate the possible effects of leaf wetting on plant gas exchange, we analysed the leaf surface microclimate following leaf wetting and assessed the capacity for foliar water uptake. We also examined leaf water repellency to evaluate the relationship between leaf surface hydrophobicity and gas exchange in wetted leaves.

\section{Materials and methods}

Plant materials and growth conditions: Tomato (Solanum lycopersicum L.), cultivar 'Hausu-momotaro' (Takii \& Co. Ltd., Kyoto, Japan) was used as plant materials. This cv. presents a determined growth pattern reported in other studies (Takahata and Miura 2017). The seeds were sown in plastic pots (9-cm diameter) filled with vermiculite at the beginning of September 2017. The seeds were germinated and grown in a phytotron glass room (air temperature of $25^{\circ} \mathrm{C}$, relative humidity of $70 \%$ ) located at the Faculty of Agriculture, Kyushu University $\left(33^{\circ} 37^{\prime} \mathrm{N}, 130^{\circ} 25^{\prime} \mathrm{E}\right)$. The plants were grown with a standard nutrient solution (Otsuka AgriTechno Co. Ltd., Japan) with an electrical conductivity of $2.0 \mathrm{dS} \mathrm{m}^{-1}$. The nutrient solution contains $17.1 \mathrm{mmol}$ $\left(\mathrm{NO}_{3}{ }^{-}\right) \mathrm{L}^{-1}, 1.1 \mathrm{mmol}\left(\mathrm{PO}_{4}{ }^{3-}\right) \mathrm{L}^{-1}, 1.6 \mathrm{mmol}\left(\mathrm{SO}_{4}{ }^{2-}\right) \mathrm{L}^{-1}$, $8.4 \mathrm{mmol}\left(\mathrm{K}^{+}\right) \mathrm{L}^{-1}, 1.5 \mathrm{mmol}\left(\mathrm{Mg}^{2+}\right) \mathrm{L}^{-1}$, and $3.9 \mathrm{mmol}\left(\mathrm{Ca}^{2+}\right)$ $\mathrm{L}^{-1}$. At the beginning of October 2017 , the plants were transferred to larger plastic pots (8-L volume) filled with vermiculite and grown with the nutrient solution in an experimental greenhouse at Kyushu University. All lateral stems were eliminated at the beginning of its budding. The tenth leaf stage of tomato plants (counted from the base of the plant) were used for all experiments, because some leaves near stem base were cut off few days before the experiments to attach the sap flow sensor.

In the greenhouse, meteorological elements, such as PPFD, air temperature $\left(T_{\mathrm{A}}\right)$, and relative humidity $(\mathrm{RH})$ were measured with a quantum sensor (CAP-SQ-110, Apogee Instruments, Logan, UT, USA), and a temperaturehumidity sensor (HMP60, Vaisala, Helsinki, Finland), respectively. All of the sensors were placed at the centre of the greenhouse, and data were recorded with a data logger (GL820, Graphtec Corporation, Yokohama, Japan) at 10-min intervals. Vapor pressure deficit (VPD) was calculated from $T_{\mathrm{A}}$ and $\mathrm{RH}$. Environmental control equipment, such as ventilation windows (side and roof windows) and a heat pump, were operated automatically with a control system according to the $T_{\mathrm{A}}$ in the greenhouse, greenhouse $T_{\mathrm{A}}$ was maintained within the $15-30^{\circ} \mathrm{C}$ range.

Leaf wetting treatments: The plants were divided into two treatment groups in the same greenhouse. One was the wet treatment and the other was the control treatment. In the wet treatment, the adaxial surface of leaves was fully wetted once an hour from 10:00 to 14:00 h manually (takes less than 3 min to wet leaves) using a mist sprayer (Maista-726, Maruhachi Industrials, Tokyo, Japan). Leaves were misted from the upper side of the leaves to avoid the abaxial side of the leaves from wetting. In the control treatment, plants were not wetted but remained in normal conditions. Leaf wetting treatments were conducted on the same days as gas-exchange experiment $(26,27,31$ October; 1, 3 November 2017).

Gas exchange and leaf surface microclimate measurements: Gas-exchange measurements were conducted using the whole-plant chamber system described by Yasutake et al. (2018), which can independently evaluate the transpiration and evaporation rates of leaf surface water by combining a stem heat balance method and chamber method when the plants are wetted. Transpiration rate $(E)$ of wetted plants was measured with a sap flow sensor (SGB-10WS, Dynamax, Houston, TX, USA) attached to the stem base. Evapotranspiration (transpiration from a plant and evaporation of leaf surface water) rate was evaluated by the gas balance of inflowing and outflowing $\mathrm{H}_{2} \mathrm{O}$ gas concentration. $\mathrm{H}_{2} \mathrm{O}$ gas concentration was calculated from $T_{\mathrm{A}}$ and $\mathrm{RH}$ measured with a temperature-humidity sensor (HMP60, Vaisala, Helsinki, Finland). When plants 
were not wetted, $E$ was measured by both the sap flow sensor and the gas balance of chamber. Photosynthetic rate $\left(P_{\mathrm{N}}\right)$ was evaluated by the gas balance of $\mathrm{CO}_{2}$ gas concentration which was measured with an infrared gas analyser (LI-820, LI-COR Biosciences, Lincoln, NE, US). Vapor pressure near leaf surface $\left(e_{\mathrm{A}}\right)$ was calculated from $T_{\mathrm{A}}$ and $\mathrm{RH}$ measured at $3 \mathrm{~cm}$ above leaf surface with three temperature-humidity sensors (THA-3151, T\&D Corporation, Matsumoto, Japan) and recorded with a data logger (TR-72ui, T\&D Corporation, Matsumoto, Japan). Leaf temperature $\left(T_{\mathrm{L}}\right)$ was measured with a copperconstantan thermocouple at three different leaves and used for calculating leaf vapor pressure $\left(e_{\mathrm{L}}\right)$. Leaf to air vapor pressure deficit $\left(\mathrm{VPD}_{\text {air-to-leaf }}\right)$ was evaluated as $e_{\mathrm{L}}-e_{\mathrm{A}}$ and leaf conductance $\left(g_{\mathrm{L}}\right)$ was evaluated as $E \times P /\left(e_{\mathrm{L}}-e_{\mathrm{A}}\right)$, where $P$ is the atmospheric pressure. Intercellular $\mathrm{CO}_{2}$ concentration $\left(C_{\mathrm{i}}\right)$ was also evaluated as $C_{\mathrm{a}}-P_{\mathrm{N}} / g_{\mathrm{L}} \times 1.6$, where $C_{\mathrm{a}}$ is the atmospheric $\mathrm{CO}_{2}$ concentration. All data (except the data of $e_{\mathrm{A}}$ ) were recorded with a program data logger (CR-1000, Cambell Scientific Inc., Logan, UT, US). The chamber was placed in the greenhouse and covered with sheets to provide shade from natural light. Twelve LED (LLM031, Stanley Electric Co. Ltd., Tokyo, Japan) bulbs were used as the light source. The wavelength of LED is $400-800 \mathrm{~nm}$ with two peaks in light intensity at 450 and $550 \mathrm{~nm}$. More detailed characteristics of the LED are described in Hidaka et al. (2013). Average horizontal distribution PPFD at the middle height of the chamber (at the height of the $5^{\text {th }}$ or $6^{\text {th }}$ leaf of a $10^{\text {th }}$ leaf stage tomato plant) was approximately $850 \mu \mathrm{mol}$ (photon) $\mathrm{m}^{-2} \mathrm{~s}^{-1}$. The $\mathrm{CO}_{2}$ concentration was maintained at $400 \pm 0.8 \mu \mathrm{mol} \mathrm{mol}^{-1}$, and air temperature was allowed to vary naturally with changes in the greenhouse air conditions. The tomato plants were divided into two treatment groups, consisting of a wet treatment (wet; plants were wetted by misting hourly from 10:00 to $14: 00 \mathrm{~h}$ ) and a control treatment (control; plants were not wetted). Leaf surface microclimate $\left(e_{\mathrm{A}}, T_{\mathrm{L}}\right.$, $\left.e_{\mathrm{L}}, \mathrm{VPD}_{\text {air-to-leaf }}\right)$ and plant gas exchange $\left(E, g_{\mathrm{L}}, P_{\mathrm{N}}\right)$ were measured in the morning (10:00-11:00 h; the time when gas exchange is assumed to be most active) and afternoon (13:00-14:00 h; the time when gas exchange is inactive due to midday depression) on clear days $(26,27,31$ October; 1, 3 November 2017). All of the day and time were expressed as Japan Standard Time.

Leaf water potential measurements: To evaluate the effects of leaf wetting on whole-plant water relations, we measured leaf water potential $\left(\Psi_{\mathrm{w}}\right)$ with a Scholandertype pressure chamber (Mdel600, PMS Instruments, Albany, OR, USA) at the same time as the gas exchange was measured. Plants of the same growth stage as those used for gas-exchange measurement were prepared. These plants were only used for measuring $\Psi_{\mathrm{w}}$ in order to avoid influencing gas exchange due to the destructive methods used when measuring $\Psi_{\mathrm{w}}$.

Leaf surface properties: To evaluate the relationship between leaf wetting and leaf morphological traits, we examined the amount of water retained on the leaf surface and the contact angle of a water droplet; the contact angle was used for determining leaf water repellency, as lower contact angles are indicative of leaves that are more wettable (Aryal and Neuner 2010). All measurements were conducted in fully expanded, recently matured leaves of $10^{\text {th }}$ leaf stage tomato plants.

The amount of water retained on the leaf surface was evaluated by comparing the mass changes of a nontreated leaf and a misted leaf. A tomato leaf was sampled, and the cut section was immediately sealed, after which the leaf was weighed on an electronic balance $(F X-1200 i, A \& D$ Company Ltd., Tokyo, Japan). The adaxial surface of the leaf was then misted with a sprayer, and the wetted leaf was weighed again.

Leaf water repellency was assessed by determining the contact angle of a water droplet on the adaxial surface of the leaf (Matos and Rosado 2016). A leaflet of tomato leaf was fixed onto a flat styrofoam platform; then a $5-\mu \mathrm{L}$ droplet of water was placed on the leaf surface using a micropipette (Finnpipette F1, Thermo Fisher Scientific, Finland) and a photograph of the water droplet on the horizontal leaf surface was taken with the digital camera (D3100, Nikon, Tokyo, Japan). The contact angle of water droplet was determined using the free software ImageJ v. 1.51 .

Measurement of foliar water uptake: The capacity for foliar water uptake was evaluated using the method described by Limm et al. (2009), by either misting the leaf surface or submerging a leaflet in water. The tomato leaflet was sampled $2 \mathrm{~h}$ after sunset, and the cut section was immediately sealed. We measured the initial mass of the leaflet (M1), and then the adaxial surface of the leaflet was either misted with a sprayer or submerged in distilled water. The misted leaflet was kept in darkness for $20 \mathrm{~min}$, and the submerged leaflet was kept submerged in water for $180 \mathrm{~min}$. The $20 \mathrm{~min}$ period was determined by gas-exchange measurements, as we visually observed during the experiment that misted leaves dried within approximately $20 \mathrm{~min}$, and $180 \mathrm{~min}$ of submergence was in line with the procedures used in previous studies (Limm et al. 2009, Matos and Rosado 2016). This allowed us to compare the capacity for foliar water uptake of tomato leaf with other plant species. After 20 or $180 \mathrm{~min}$, water on the leaf surface was removed with a paper towel and the leaf was reweighed (M2). To account for any potential error due to residual water on the leaf surface, the leaflet was allowed to dry naturally for $5 \mathrm{~min}$, and the mass was measured once more (M3). The same leaflet was either momentarily wetted by misting or resubmerged and dried with a paper towel and then weighed (M4). This rapid rewetting did not allow sufficient time for foliar water uptake, and thus any increase in mass associated with rewetting represented the residual water on the leaf surface. We calculated the amount of foliar water uptake (FWU) as follows: $\mathrm{FWU}=(\mathrm{M} 2-\mathrm{M} 1)-(\mathrm{M} 4-\mathrm{M} 3)$.

Statistical analysis: Data normality was checked by the Shapiro-Wilk's test. The effects of treatment (control and wet treatment), measurement period (morning 10:00-11:00 h and afternoon 13:00-14:00 h), and their interaction on 
leaf surface microclimate $\left(e_{\mathrm{A}}, T_{\mathrm{L}}, e_{\mathrm{L}}, \mathrm{VPD}_{\text {air-to-leaf }}\right)$ and plant physiological response $\left(E, \Psi_{\mathrm{w}}, g_{\mathrm{L}}, P_{\mathrm{N}}, C_{\mathrm{i}}\right)$ were tested with two-way analysis of variance $(A N O V A)$. When significant differences were detected between treatments (control and wet treatment) or measurement periods (morning and afternoon) we applied the Student's $t$-test for each effect.

The one-sample $t$-test was used to determine whether the foliage from each leaf wetness duration (20-min misting or 180 -min submergence) absorbed significantly more than $0 \mathrm{mg}$ (water) per unit leaf area. All of the statistical analyses were conducted by using statistical program $R$ (ver. 3.2.4).

\section{Results}

Environmental conditions: Fig. 1 shows average diurnal changes in PPFD, $T_{\mathrm{A}}$, and VPD in the greenhouse during the experimental days of gas-exchange measurements. PPFD in the greenhouse slightly increased over the period 7:00-9:00 $\mathrm{h}$ and then sharply increased thereafter, most likely because the greenhouse was shaded by an adjacent building during the 7:00-9:00 $\mathrm{h}$ period. A maximum PPFD of 1,050 $\mu \mathrm{mol} \mathrm{m}{ }^{-2} \mathrm{~s}^{-1}$ was recorded at 12:00 h. $T_{\mathrm{A}}$ and VPD in the greenhouse exhibited similar diurnal changes; both

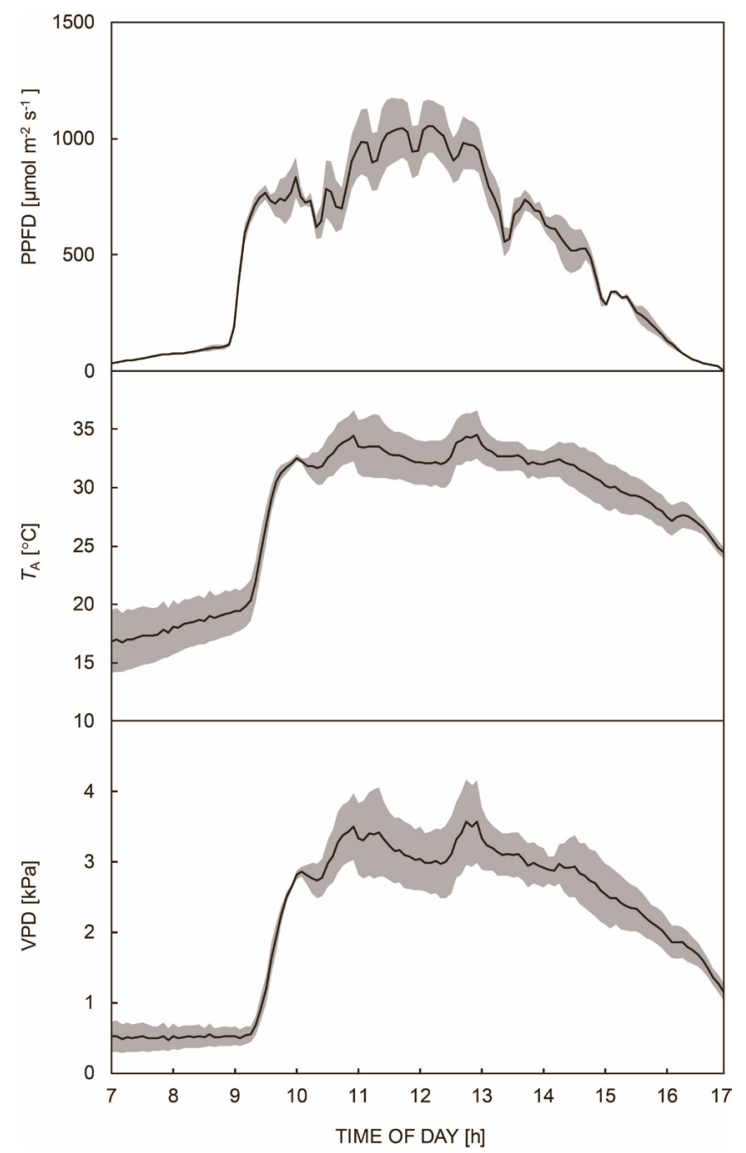

Fig. 1. Diurnal changes in photosynthetic photon flux density (PPFD), air temperature $\left(T_{\mathrm{A}}\right)$, and vapor pressure deficit (VPD) in a greenhouse throughout the experimental period. The black solid line represents the average values of $5 \mathrm{~d}$ of gas-exchange measurement; gray shading indicates the standard errors $(n=5)$.
$T_{\mathrm{A}}$ and VPD sharply increased as the sun shone on the greenhouse and remained at approximately $32-34^{\circ} \mathrm{C}$ and 3-3.4 kPa, respectively, until 14:00 h.

Effect of leaf wetting on leaf surface microclimate: A significant difference of the effect of wet treatment was detected in $e_{\mathrm{A}}, T_{\mathrm{L}}, e_{\mathrm{L}}$, and $\mathrm{VPD}_{\text {air-to-leaf }}$ by two-way $A N O V A$ test (Table 1). On the other hand, a significant difference in the measurement time period (morning 10:00-11:00 $\mathrm{h}$ and afternoon 13:00-14:00 h) was only detected in $\mathrm{VPD}_{\text {air-to-leaf. }}$ Therefore, we only compared the significant difference between the two treatments (control and wet) in $e_{\mathrm{A}}, T_{\mathrm{L}}, e_{\mathrm{L}}$, and we compared the effects of treatments and measurement time periods in $\mathrm{VPD}_{\text {air-to-leaf }}$ by the Student's $t$-test. In the morning, leaf wetting significantly increased $e_{\mathrm{A}}$ near leaf surfaces of the wet treated plants $(2.9 \mathrm{kPa})$ by $21 \%$ compared with that in the control treatment $(2.4 \mathrm{kPa})$, whereas in the afternoon, a significant difference was not detected between both treatments (Fig. $2 A$ ). There was no significant difference in $T_{\mathrm{L}}$ between the wet and the control treatments $\left(28\right.$ and $\left.30^{\circ} \mathrm{C}\right)$ in the morning. In the afternoon, however, $T_{\mathrm{L}}$ in the control treatment $\left(32^{\circ} \mathrm{C}\right)$ was significantly higher than that in the wet treatments $\left(29^{\circ} \mathrm{C}\right)$ (Fig. $2 B$ ). $e_{\mathrm{L}}$ (calculated from $T_{\mathrm{L}}$ ) exhibited the same pattern as $T_{\mathrm{L}}$ (Fig 2C). As a result of the effects of leaf wetting, $\mathrm{VPD}_{\text {air-to-leaf }}$ in the wet treatment decreased by 52 and $56 \%$ in the morning and the afternoon, respectively, compared with that in the control (Fig. 2D). In the control treatment, $\mathrm{VPD}_{\text {air-to-leaf }}$ was $32 \%$ higher in the afternoon than in the morning.

Effect of leaf wetting on whole-plant gas exchange and leaf water potential: Significant differences of the effects of the wet treatment and measurement period were detected in $E, \Psi_{\mathrm{w}}, g_{\mathrm{L}}, P_{\mathrm{N}}, C_{\mathrm{i}}$ by two-way $A N O V A$ test (Table 1 ). Significant interactions of 'treatment $\times$ measurement period' were detected in $E, \Psi_{\mathrm{w}}, P_{\mathrm{N}}$, but not in $g_{\mathrm{L}}$. However, the physiological parameters were not only affected by the leaf wetting treatment or measurement period but they were also affected by other potential physiological parameters and hysteresis effect of environmental factors along the day, which makes difficult to give a reasonable explanation based on biological mechanism. Therefore, we compared the significant difference between the two treatments and measurement time periods (morning 10:00-11:00 h and afternoon 13:00-14:00 h) separately. $E$ was higher in leaves from the control than that in leaves from the wet treatment, but no significant difference was detected between the two treatments in the afternoon (Fig. $3 A$ ). In the control, $E$ was $32 \%$ lower in the afternoon than that in the morning, whereas in the wet, $E$ remained at about the same value between the morning and the afternoon. In the morning, $\Psi_{\mathrm{w}}$ in the control treatment $(-0.58 \mathrm{MPa})$ was significantly lower than that of the wet treatment $(-0.42 \mathrm{MPa})$ (Fig. $3 \mathrm{~B})$, however, such difference in leaf water potential is not physiologically relevant for tomato plants.

In the afternoon, $\Psi_{\mathrm{w}}$ in the control decreased to $-1.3 \mathrm{MPa}$ from the morning value, whereas in the wet treatment, $\Psi_{\mathrm{w}}$ remained at around the same value in the 
Table 1. Results of two-way ANOVA for effects of treatment, measurement period, and their interactions. $e_{\mathrm{A}}-$ vapor pressure $(n=5)$, $T_{\mathrm{L}}$ - leaf temperature $(n=5), e_{\mathrm{L}}$ - leaf vapor pressure $(n=5), \mathrm{VPD}_{\text {air-to-leaf }}$ - leaf-to-air vapor pressure deficit $(n=5), E-$ transpiration rate $(n=5), \Psi_{\mathrm{w}}$ - leaf water potential $(n=6), g_{\mathrm{L}}$ - leaf conductance $(n=5), P_{\mathrm{N}}$ - photosynthetic rate $(n=5), C_{\mathrm{i}}-$ intercellular $\mathrm{CO}_{2}$ concentration $(n=5)$.

\begin{tabular}{|c|c|c|c|c|c|c|c|c|c|}
\hline \multirow[t]{2}{*}{ Parameters } & \multicolumn{3}{|c|}{ Treatment } & \multicolumn{3}{|c|}{ Measurement period } & \multicolumn{3}{|c|}{$\begin{array}{l}\text { Treatment } \times \text { Measurement } \\
\text { period }\end{array}$} \\
\hline & d.f. & $\mathrm{F}$ & $P$ & d.f. & $\mathrm{F}$ & $P$ & d.f. & $\mathrm{F}$ & $P$ \\
\hline$e_{\mathrm{A}}[\mathrm{kPa}]$ & 1 & 9.42 & $<0.01$ & 1 & 0.20 & 0.658 & 1 & 0.07 & 0.797 \\
\hline$T_{\mathrm{L}}\left[{ }^{\circ} \mathrm{C}\right]$ & 1 & 8.24 & $<0.05$ & 1 & 3.18 & 0.096 & 1 & 1.20 & 0.292 \\
\hline$e_{\mathrm{L}}[\mathrm{kPa}]$ & 1 & 8.39 & $<0.05$ & 1 & 3.65 & 0.076 & 1 & 1.42 & 0.253 \\
\hline $\mathrm{VPD}_{\text {air-to-leaf }}[\mathrm{kPa}]$ & 1 & 52.51 & $<0.001$ & 1 & 6.56 & $<0.05$ & 1 & 2.47 & 0.138 \\
\hline$E\left[\operatorname{mmol}\left(\mathrm{H}_{2} \mathrm{O}\right) \mathrm{m}^{-2} \mathrm{~s}^{-1}\right]$ & 1 & 10.76 & $<0.01$ & 1 & 10.76 & $<0.01$ & 1 & 14.93 & $<0.01$ \\
\hline$\Psi_{\mathrm{w}}[\mathrm{MPa}]$ & 1 & 52.08 & $<0.001$ & 1 & 35.76 & $<0.001$ & 1 & 19.10 & $<0.001$ \\
\hline$g_{\mathrm{L}}\left[\operatorname{mol}\left(\mathrm{H}_{2} \mathrm{O}\right) \mathrm{m}^{-2} \mathrm{~s}^{-1}\right]$ & 1 & 7.97 & $<0.05$ & 1 & 11.16 & $<0.01$ & 1 & 1.51 & 0.239 \\
\hline$P_{\mathrm{N}}\left[\mu \mathrm{mol}\left(\mathrm{CO}_{2}\right) \mathrm{m}^{-2} \mathrm{~s}^{-1}\right]$ & 1 & 4.83 & $<0.05$ & 1 & 14.64 & $<0.01$ & 1 & 6.28 & $<0.05$ \\
\hline$C_{\mathrm{i}}\left[\mu \mathrm{mol}\left(\mathrm{CO}_{2}\right) \mathrm{mol}^{-1}\right]$ & 1 & 8.45 & $<0.05$ & 1 & 5.17 & $<0.05$ & 1 & 2.29 & 0.152 \\
\hline
\end{tabular}

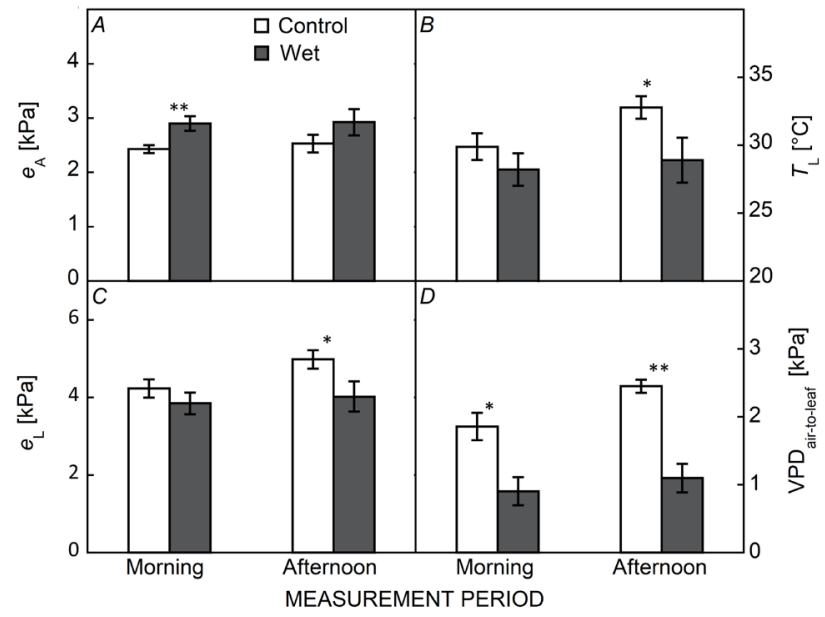

Fig. 2. Vapor pressure $\left(e_{\mathrm{A}}\right)(A)$, leaf temperature $\left(T_{\mathrm{A}}\right)(B)$, leaf vapor pressure $\left(e_{\mathrm{L}}\right)(C)$, and leaf-to-air vapor pressure deficit $\left(\mathrm{VPD}_{\text {air-to-leaf }}\right)(D)$ in the morning $(10: 00-11: 00 \mathrm{~h})$ and in the afternoon $(13: 00-14: 00 \mathrm{~h})$ periods in tomato plants subjected to control and wet treatments. Environmental conditions in the chamber were maintained at a constant PPFD of $850 \mu \mathrm{mol} \mathrm{m}^{-2} \mathrm{~s}^{-1}$ and a $\mathrm{CO}_{2}$ concentration of $400 \mu \mathrm{mol} \mathrm{mol}{ }^{-1}$. Means $\pm \mathrm{SE}(n=5)$ are shown. ${ }^{*}(P<0.05),{ }^{* *}(P<0.01),{ }^{* * *}(P<0.001)$ denote significant differences between the treatments (control and wet) by Student's $t$-test.

afternoon $(-0.52 \mathrm{MPa})$ as in the morning. $\Psi_{\mathrm{w}}$ in the wet was significantly higher than that in the control in the afternoon. Similar patterns were detected for $g_{\mathrm{L}}$ and $P_{\mathrm{N}}$; in the morning, there was no significant difference in $g_{\mathrm{L}}$ and $P_{\mathrm{N}}$ between the wet and control treatments (Fig. 3C,D), but in the afternoon, $g_{\mathrm{L}}$ and $P_{\mathrm{N}}$ in the wet was significantly higher than in the control, by 83 and $20 \%$, respectively. In the control, $g_{\mathrm{L}}$ and $P_{\mathrm{N}}$ were 40 and $22 \%$ lower in the afternoon than that in the morning, respectively. In the morning period, no significant difference was detected between $C_{\mathrm{i}}$ of the control and wet treatments. However, $C_{\mathrm{i}}$ in the control treatment significantly decreased in the afternoon, and it was $12 \%$ lower than that in the wet treatment.

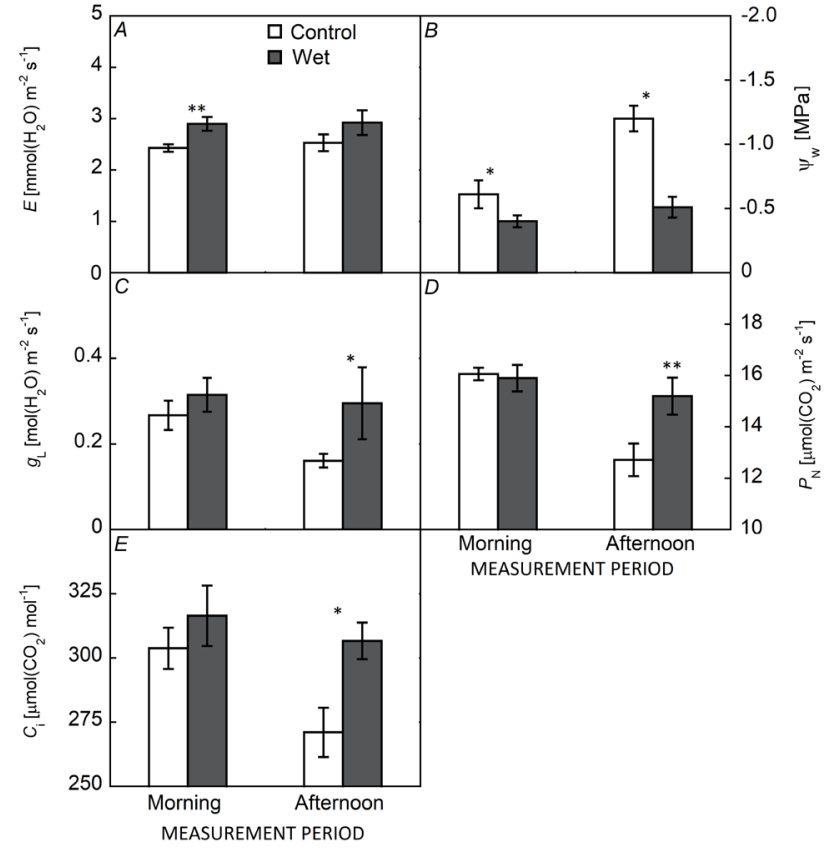

Fig. 3. Transpiration rate $(E)(A)$, leaf water potential $\left(\Psi_{\mathrm{w}}\right)(B)$, leaf conductance $\left(g_{\mathrm{L}}\right)(C)$, photosynthetic rate $\left(P_{\mathrm{N}}\right)(D)$, and intercellular $\mathrm{CO}_{2}$ concentration $\left(C_{\mathrm{i}}\right)(E)$ in the morning $(10: 00-11: 00 \mathrm{~h})$ and in the afternoon (13:00-14:00 h) periods in tomato plants subjected to control and wet treatments. Environmental conditions in the chamber were maintained at a constant PPFD of $850 \mu \mathrm{mol} \mathrm{m}^{-2} \mathrm{~s}^{-1}$ and a $\mathrm{CO}_{2}$ concentration of $400 \mu \mathrm{mol} \mathrm{mol}{ }^{-1}$. Means $\pm \operatorname{SE}\left[E(n=5), \Psi_{\mathrm{w}}(n=6), g_{\mathrm{L}}(n=5), P_{\mathrm{N}}(n=5), C_{\mathrm{i}}\right.$ $(n=5)]$ are shown. ${ }^{*}(P<0.05),{ }^{* *}(P<0.01),{ }^{* * *}(P<0.001)$ denote significant differences between the treatments (control and wet) by Student's $t$-test.

Fig. $4 A$ shows the time course changes in $V_{P D}$ air-to-leaf among plants in the leaf wetting treatment. VPD $\mathrm{D}_{\text {air-to-leaf }}$ was lower soon after leaves were wetted and increased as the leaf surface water dried. The evapotranspiration rate (ET), as estimated by measuring changes in the gas balance of the chamber, and $E$, as measured with a sap flow sensor, 


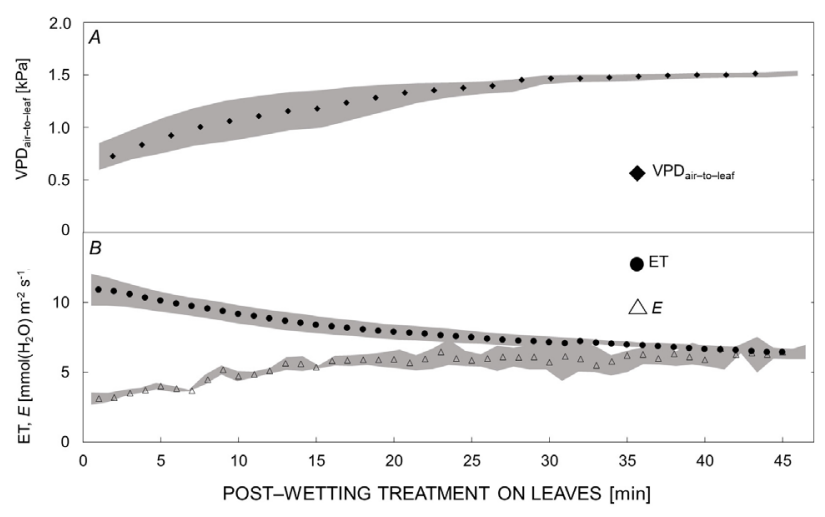

Fig. 4. Time course changes of leaf-to-air vapor pressure deficit (VPD air-to-leaf; solid rhombus; $A$ ), evapotranspiration rate (ET; solid circle; $B)$, and transpiration rate $(E$; open triangle $; B)$ after leaf wetting, as measured using the whole-plant chamber system. Environmental conditions in the chamber were maintained at a constant PPFD of $850 \mu \mathrm{mol} \mathrm{m} \mathrm{m}^{-2} \mathrm{~s}^{-1}$ and a $\mathrm{CO}_{2}$ concentration of $400 \mu \mathrm{mol} \mathrm{mol}^{-1}$. Gray shading indicates the standard errors of means $(n=3)$.

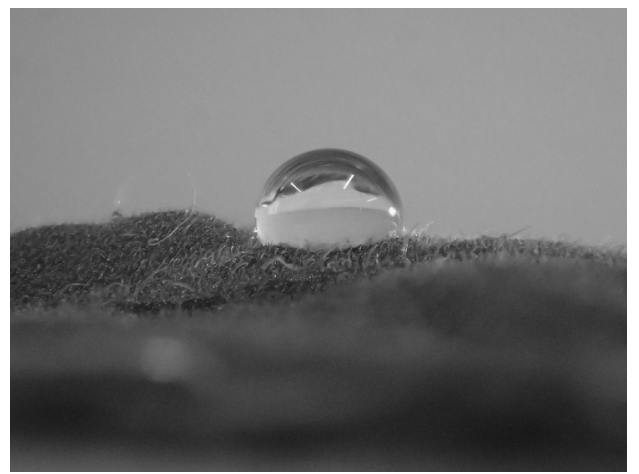

Fig. 5. Photograph of water droplet on the leaf surface.

exhibited different responses to leaf wetting (Fig. 4B). ET was higher immediately after leaf wetting and gradually decreased, whereas $E$ was lower immediately after leaf wetting and gradually increased. The values for the two different measurements began to converge as leaf surface water dried, and eventually were the same.

Leaf surface properties and foliar water uptake: Leaf surface properties and capacity for foliar water uptake are shown in Table 2. The amount of water retained on the leaf surface of tomato leaves was $10.5 \pm 0.82 \mathrm{mg} \mathrm{cm}^{-2}$, and the contact angle of tomato leaf was $105 \pm 2.5^{\circ}$. Based on the criteria of Aryal and Neuner (2010), the tomato leaf can, therefore, be classified as a 'wettable leaf'.
Foliar water uptake was not observed following wetting the adaxial surface of tomato leaf for $20 \mathrm{~min}$, but foliar water uptake at a rate of $2.0 \pm 0.15 \mathrm{mg} \mathrm{cm}^{-2}$ was observed following submergence of the leaf for $180 \mathrm{~min}$.

\section{Discussion}

We observed midday depression of photosynthesis with decreasing $g_{\mathrm{L}}$ (Fig. $3 C, D$ ) in tomato plants, similar to what has been reported for other horticultural crops $(\mathrm{Hu}$ et al. 2009, Pelletier et al. 2016). The reduction in $g_{\mathrm{L}}$ was very likely due to stomatal closure, because the air flow in the chamber was constant throughout the experimental period, and thus, leaf boundary layer conductance was also assumed to be constant. The stomatal closure may one of the major causes of midday depression since $C_{\mathrm{i}}$ in the control treatment decreased in the afternoon. It has been previously established that stomatal conductance

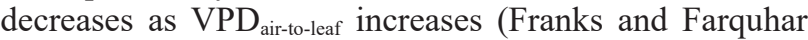
1999), and therefore, increasing VPD air-to-leaf $_{\text {could be one of }}$ the causes of stomatal closure (Fig. 2D). Another possible cause of stomatal closure is decrease in $\Psi_{\mathrm{w}}$ because of transpiration water loss (Fig. 3B). Yasutake et al. (2015) reported that in sweet pepper, decreasing $\mathrm{VPD}_{\text {air-to-leaf }}$ in the afternoon did not stimulate stomatal opening. Moreover, Lee et al. (2012) observed that cell turgor continued to decline in the afternoon even though the soil was wellwatered, and that cell turgor was not completely recovered at predawn of the next day. It can, therefore, be assumed that hysteresis transpiration water loss may be involved in midday depression of photosynthesis.

Although positive effects of leaf wetting have been previously shown to increase leaf water content, and thereby improve photosynthesis and growth in woody plants (Cassana and Dillenburg 2013, Eller et al. 2016), how it affects horticultural crops is unclear. In the present study, leaf wetting significantly reduced $\mathrm{VPD}_{\text {air-to-leaf }}$ by increasing $e_{\mathrm{A}}$ and suppressing the rising $T_{\mathrm{L}}$ (Fig. $2 A, B, D$ ), and thus reduced $E$ (Fig. $3 A$ ). There was no foliar water uptake within $20 \mathrm{~min}$ of leaf wetting, and thus, the higher $\Psi_{\mathrm{w}}$ observed in the wet treatment in the afternoon was most likely due to lower $E$. $C_{\mathrm{i}}$ in the control treatment decreased in the afternoon from the morning, however, $C_{\mathrm{i}}$ in the wet treatment was not decreased in the afternoon. Together, these results suggest that leaf wetting alleviates transpiration water loss and helps plants maintain appropriate water status through its effects on leaf surface microclimates and increasing $P_{\mathrm{N}}$ via the stimulation of stomatal apertures (Fig. 3C,D). These results are consistent with those of Ozawa (1989), who also found that leaf wetting alleviated transpiration water loss and improved water

Table 2. Leaf surface properties and foliar water uptake of the adaxial surface of tomato leaf. Fully expanded, recently matured leaves of $10^{\text {th }}$ leaf stage tomato plants were used for all measurements. Means $\pm \mathrm{SE}$ are shown in the table and ${ }^{* *}$ denote statistically significant difference at $P<0.01$ by one-sample $t$-test.

\begin{tabular}{llll}
\hline $\begin{array}{l}\text { Amount of retained water } \\
{\left[\mathrm{mg} \mathrm{cm}^{-2}\right]}\end{array}$ & $\begin{array}{l}\text { Contact angle of } \\
\text { water droplet }\left[^{\circ}\right]\end{array}$ & $\begin{array}{l}\text { Foliar water uptake after } \\
20 \text {-min misting }\left[\mathrm{mg} \mathrm{cm}^{-2}\right]\end{array}$ & $\begin{array}{l}\text { Foliar water uptake after 180-min } \\
\text { submergence }\left[\mathrm{mg} \mathrm{cm}^{-2}\right]\end{array}$ \\
\hline $10.50 \pm 0.82$ & $105.0 \pm 2.5$ & None & $2.00 \pm 0.15^{* *}$ \\
\hline
\end{tabular}


status, and subsequently photosynthesis, in tomato plants (Yokoyama et al. 2018). Furthermore, leaf wetting may contribute to increase plant growth and fruits yield under limited water source or high evaporative demand conditions by improving plant water status, and thus maintaining turgor driven cell expansion (Romero-Aranda et al. 2002).

Leaf wetting has often been regarded as having negative effects, especially in 'wettable leaf' plants, because leaf surface water physically blocks $\mathrm{CO}_{2}$ diffusion into carboxylation sites, and thus, inhibits photosynthesis (Brewer and Smith 1994, Ishibashi and Terashima 1995, Hanba et al. 2004). Here, we found that leaf wetting had positive effects on tomato plants despite tomato leaf being classified as a 'wettable leaf' type (Table 1). This is most likely because of the asymmetric distribution of the stomata on the adaxial and abaxial leaf surfaces; stomata are more abundant on the abaxial side of the tomato leaf (Jones 2013), and we only wetted the adaxial side of the leaf. Leaf surface hair may also play an important role in leaf surface wetting, as leaf hairs may interfere in contact between leaf surface and water droplets, which can lead to blockage of gas exchange. In addition, we wetted the leaf once in every hour (10:00-14:00 h), whereas we visually observed that the water retained on the leaf following leaf wetting evaporated within approximately $20 \mathrm{~min}$. Thus, the effect of water film on $\mathrm{CO}_{2}$ diffusion may have been diminished in this study.

Tomato leaves exhibited foliar water uptake within $180 \mathrm{~min}$ of submergence in water. The significance of foliar water uptake for plant water status has previously been reported for many woody plants (Limm et al. 2009, Simonin et al. 2009, Goldsmith et al. 2017). Our results suggest that foliar water uptake is a common process among plant species when the water potential gradient between the leaf surface and the inside of the leaf is large enough for water to diffuse over the resistance presented by the leaf surface layer. However, it should be noted that evaluation based on complete submergence may ignore the effects of leaf surface morphological traits. In horticultural crops, many studies have focused on the foliar uptake of 'nutrient solution', known as foliar application (Kaya et al. 2001, Zaller 2006). However, recent studies on foliar application have largely focused on the concentration gradients between leaf surface nutrient solutes and the inside of the leaf as a driving force for foliar uptake of nutrient solutes, and have failed to take leaf water status into consideration. Foliar application may be more effective when applied to plants with lower water potential leaf given that water potential gradients may also promote foliar uptake.

In conclusion, leaf wetting has significant impacts on plant gas-exchange rates owing to its effects on leaf surface microclimate, and foliar water uptake was not observed following temporal leaf wetting. The leaf-to-air vapor pressure deficit was lower after leaf wetting, which led to the suppression of transpiration water loss, thereby contributing to the maintenance of appropriate plant water balance. Our results suggest that leaf wetting helps alleviate stomatal closure, and thus, mitigates midday depression of photosynthesis.

\section{References}

Araya T., Noguchi K., Terashima I.: Effect of carbohydrate accumulation on photosynthesis differ between sink and source leaves of Phaseolus vulgaris L. -Plant Cell Physiol. 47: 644-652, 2006.

Aryal B., Neuner G.: Leaf wettability decreases along an extreme altitudinal gradient. - Oecologia 162: 1-9, 2010.

Ayari O., Dorais M., Gosselin A.: Daily variations of photosynthetic efficiency of greenhouse tomato plants during winter and spring. - J. Am. Soc. Hortic. Sci. 125: 235-241, 2000.

Brewer C.A., Smith W.K.: Leaf surface wetness and gas exchange in the pond lily Nuphar polysepalum (Nymphae-aceae). Am. J. Bot. 82: 1271 - 1277, 1995.

Cassana F.F., Dillenburg L.R.: The periodic wetting of leaves enhances water relations and growth of the long-lived conifer Araucaria angustifolia. - Plant Biol. 15: 75-83, 2013.

Eller C.B., Lima A.L., Oliveira R.S.: Cloud forest trees with higher foliar water uptake capacity and anisohydric behavior are more vulnerable to drought and climate change. - New Phytol. 211: 489-501, 2016.

Eller C.B., Lima A.L., Oliveira R.S.: Foliar uptake of fog water and transport belowground alleviates drought effects in the cloud forest tree species, Drimys brasiliensis (Winteraceae). New Phytol. 199: 151-162, 2013.

Flexas J., Bota J., Loreto F. et al.: Diffusive and metabolic limitations to photosynthesis under drought and salinity in $\mathrm{C}_{3}$ plants. - Plant Biol. 6: 269-279, 2004.

Franks P.J., Farquhar G.D.: A relationship between humidity response, growth form and photosynthetic operating point in $\mathrm{C}_{3}$ plants. - Plant Cell Environ. 22: 1337-1349, 1999.

Goldsmith G.R., Bentley L.P., Shenkin A. et al.: Variation in leaf wettability traits along tropical montane elevation gradient. New Phytol. 214: 989-1001, 2017.

Grassi G., Magnani F.: Stomatal, mesophyll conductance and biochemical limitations to photosynthesis as affected by drought and leaf ontogeny in ash and oak trees. - Plant Cell Environ. 28: 834-849, 2005.

Guyot G., Scoffoni C., Sack L.: Combined impacts of irradiance and dehydration on leaf hydraulic conductance: insights into vulnerability and stomatal control. - Plant Cell Environ. 35: 857-871, 2012.

Hanba Y.T., Moriya A., Kimura K.: Effect of leaf surface wetness and wettability on photosynthesis in bean and pea. - Plant Cell Environ. 27: 413-421, 2004.

He J., Austin P.T., Nichols M.A., Lee S.-K.: Elevated rootzone $\mathrm{CO}_{2}$ protects lettuce plants from midday depression of photosynthesis. - Environ. Exp. Bot. 61: 94-101, 2007.

Hidaka K., Dan K., Imamura H. et al.: Effect of supplemental lighting from different light sources on growth and yield of strawberry. - Environ. Control. Biol. 51: 41-47, 2013.

Hirasawa T., Iida Y., Ishihara K.: Dominant factors in reduction of photosynthetic rate affected by air humidity and leaf water potential in rice plants. - Jpn. J. Crop Sci. 58: 383-389, 1989.

$\mathrm{Hu}$ M.J., Guo Y.P., Shen Y.G. et al.: Midday depression of photosynthesis and effects of mist spray in citrus. - Ann. Appl. Biol. 154: 143-155, 2009.

Huber L., Gillespie T.: Modeling leaf wetness in relation to plant disease epidemiology. - Annu. Rev. Phytopathol. 30: 553-577, 1992.

Ishibashi M., Terashima I.: Effects of continuous leaf wetness on photosynthesis: adverse aspects of rainfall. - Plant Cell Environ. 18: 431-438, 1995.

Jones H.G.: Plants and Microclimate: A Quantitative Approach to Environmental Plant Physiology. $3^{\text {rd }}$ edition. Pp. 423. Cambridge University Press, Cambridge 2013. 
Kaya C., Kirnak H., Higgs D.: Enhancement of growth and normal growth parameters by foliar application of potassium and phosphorus in tomato cultivars grown at high $(\mathrm{NaCl})$ salinity. - J. Plant Nutr. 24: 357-367, 2001.

Kitano M., Eguchi H.: Dynamic analyses of water relations and leaf growth in cucumber plants under midday water deficit. Biotronics 22: 72-85, 1993

Lee K.M., Driever S.M., Heuvelink E. et al.: Evaluation of diel patters of relative changes in cell turgor of tomato plants using leaf patch clamp pressure probes. - Physiol. Plantarum 146: 439-447, 2012.

Limm E.B., Simonin K.A., Bothman A.G., Dawson T.E.: Foliar water uptake: a common water acquisition strategy for plants of the redwood forest. - Oecologia 161: 449-459, 2009.

Long S., Humphries S., Falkowski P.: Photoinhibition of photosynthesis in nature. - Annu. Rev. Plant Phys. 45: 633-662, 1994.

Mather J.R., Yoshioka G.A.: The role of climate in the distribution of vegetation. - Ann. Assoc. Am. Geogr. 58: 29-41, 1968.

Matos I.S., Rosado B.H.: Retain or repel? Droplet volume does matter when measuring leaf wetness traits. - Ann. Bot. 117: 1045-1052, 2016.

Ozawa K.: [Effect of foliar water spraying on root elongation of tomato plants.] - J. Agric. Meteorol. 45: 19-23, 1989. [In Japanese with English abstract]

Pelletier V., Pepin S., Gallichand J., Caron J.: Reducing cranberry heat stress and midday depression with evaporative cooling. Sci. Hortic.-Amsterdam 198: 445-453, 2016.

Romero-Aranda R., Soria T., Cuartero J.: Greenhouse mist im- proves yield of tomato plants grown under saline conditions. J. Am. Soc. Hortic. Sci. 127: 644-648, 2002.

Sack L., Holbrook M.N.: Leaf hydraulics. - Annu. Rev. Plant. Biol. 57: 361-381, 2006.

Schulze E.D.: Carbon dioxide and water vapor exchange in response to drought in the atmosphere and in the soil. - Ann. Rev. Plant. Physio. 37: 247-74, 1986.

Simonin K.A., Santiago L.S., Dawson T.E.: Fog interception by Sequoia sempervirens (D. Don) crowns decouples physiology from soil water deficit. - Plant. Cell Environ. 32: 882-892, 2009.

Stephenson N.: Climatic control of vegetation distribution: the role of the water balance. - Amer. Nat. 135: 649-670, 1990.

Takahata K., Miura H.: Effect of growth period and air temperature on the position of the inflorescence on the stem of tomato plants. - Hort. J. 86: 70-77, 2017.

Yasutake D., Mori M., Kitano M. et al.: Night-time leaf wetting process and its effect on the morning humidity gradient as a driving force of transpirational water loss in a semi-arid cornfield. - Biologia 70: 1485-1489, 2015.

Yasutake D., Yokoyama G., Maruo K. et al.: Analysis of leaf wetting effects on gas exchange of corn using a whole-plant chamber system. - Plant Soil Environ. 64: 233-239, 2018.

Yokoyama G., Yasutake D., Kitano M.: A preliminary experiment on the effects of leaf wetting on gas exchange in tomato leaves. - Environ. Control Biol. 56: 13-16, 2018.

Zaller J.G.: Foliar spraying of vermicornpost extracts: effects on fruit quality and indications of late-blight suppression of fieldgrown tomatoes. - Biol. Agric. Hortic. 24: 165-180, 2006.

(C) The authors. This is an open access article distributed under the terms of the Creative Commons BY-NC-ND Licence. 